\title{
El argumento antropológico de Zubiri
}

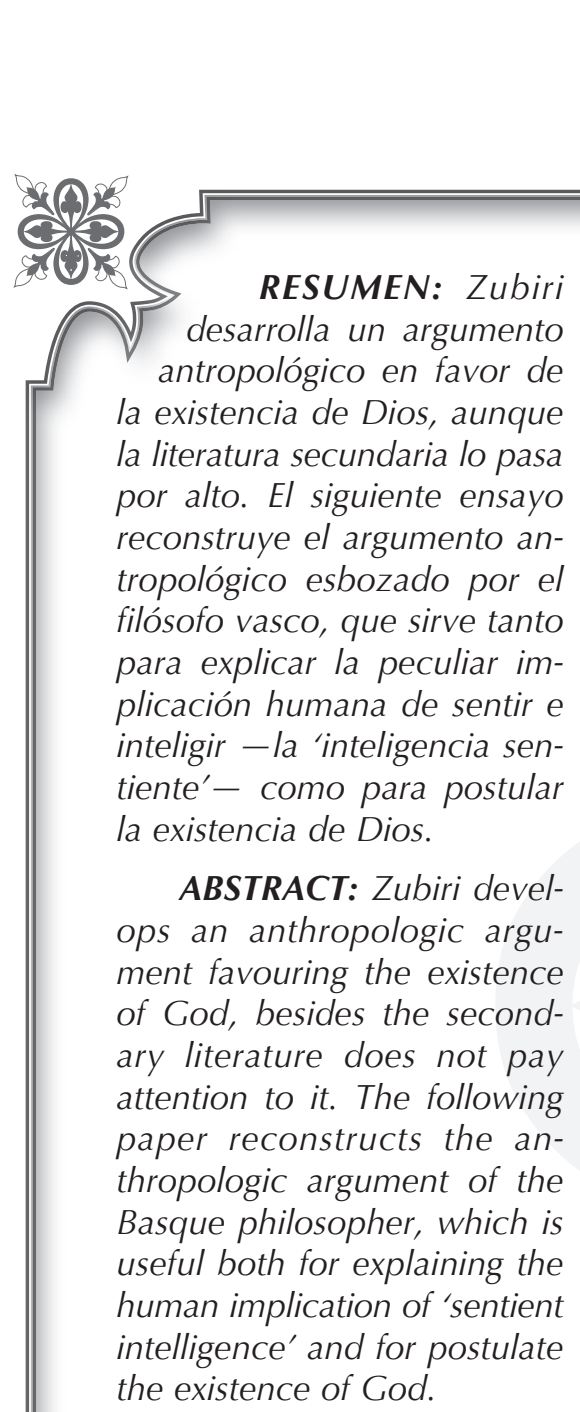

\section{Enzo Solari \\ Universidad Católica del Norte, Chile}

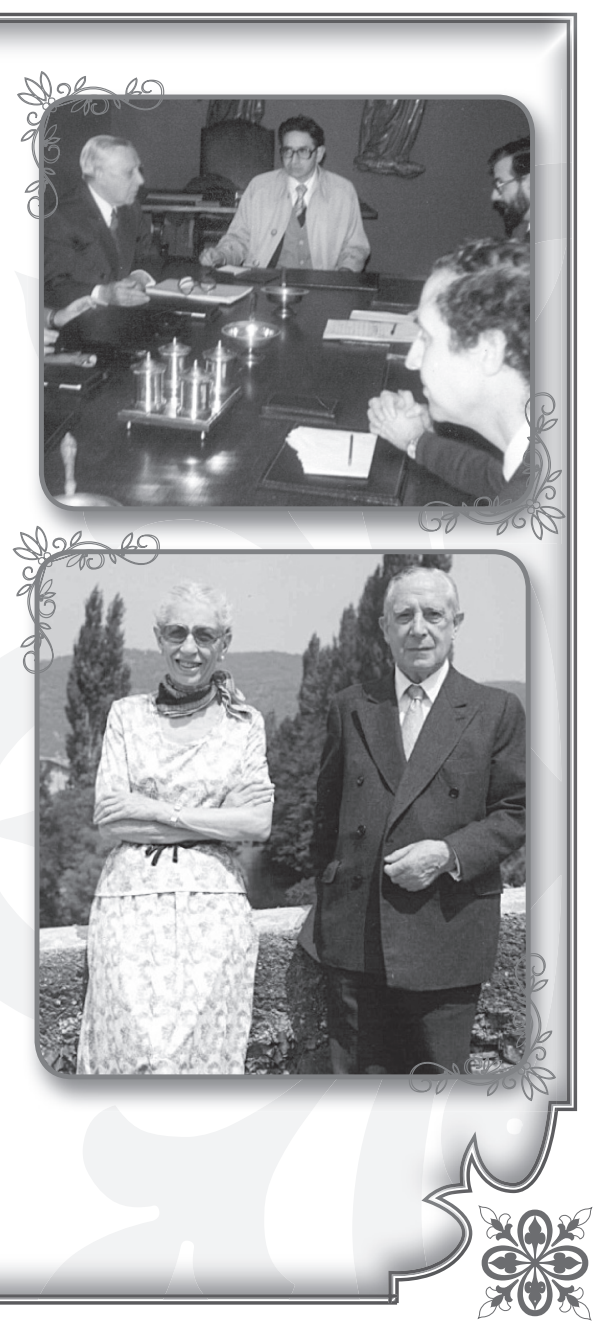

ubiri desarrolla un argumento antropológico en favor de la existencia de Dios, dentro del cual cabe plantear la difícil cuestión de la relación entre el factum de mentes como las humanas con 
la posible o necesaria realidad de Dios, vale decir, la cuestión de si el principio antrópico (sobre todo en sus versiones fuerte y final) se conecta eventual o forzosamente con la existencia de Dios o, al menos, de cierto Diseñador Inteligente de un cosmos en el que ha surgido la vida específicamente humana. Curiosamente, la literatura secundaria (hasta donde la conozco) pasa por alto semejante argumentación. Esta ausencia responde a un preciso motivo. $Y$ es que, más en general, cuando dicha literatura subraya (correctamente) que los mayores aportes filosóficos de Zubiri son fenomenológicos y radican en su análisis de la intelección -en su 'noología' - , tiende a menospreciar la argumentación específicamente metafísica de Zubiri, aquélla que ya no es descriptiva sino explicativa, constructiva. Lo cual parece especialmente claro cuando se exponen las ideas de Zubiri en torno a las religiones. Entonces, según tales intérpretes, lo que merecería la pena exponer es ante todo y par excellence esa fenomenología de la religión elaborada al hilo de la noología. En cambio, los desarrollos metafísicos (teología filosófica, racionalidad de la creencia religiosa, etc.) quedan relegados a la periferia de dicha filosofía de la religión, cuando no son descartados derechamente como anomalías ${ }^{1}$. De ahí el propósito de estas páginas: reconstruir, a lo largo de la obra de Zubiri, el descuidado argumento antropológico esbozado por el filósofo vasco tanto para explicar la peculiar implica- ción humana de sentir e inteligir -la 'inteligencia sentiente' - cuanto para postular plausiblemente la existencia de Dios.

En el texto "Transcendencia y física", de 1964, Zubiri menciona de paso la necesidad de complementar el argumento cosmológico allí desarrollado ${ }^{2}$ con el argumento antropológico: "prescindamos -por razones de método- de que tomada como explicación integral del Universo, la imagen 'científica' del estado inicial único, tendría que contener no sólo estructuras materiales, sino también aquellas otras que en su hora determinarían la aparición de los seres inteligentes $^{\prime \prime 3}$. En la trayectoria intelectual de Zubiri, no cabe duda de que el desarrollo de esta argumentación antropológica es constante y bastante más detallado que el del argumento cosmológico.

Hay aquí una primera dimensión polémica. Zubiri encuentra una suerte de 'protofenomenología' en la idea de un conocimiento implícito, vital de Dios, sostenida por la escuela que procede de Tomás de Aquino. Zubiri piensa que allí puede hallarse material para elaborar la idea de la religación, pero añade que el planteamiento de la cuestión tiene sus debilidades, sobre todo porque la argumentación se apura en demasía en dar con Dios, en hacer patente un cierto lazo esencial del espíritu humano con la divinidad, cuando lo único que analíticamente hay es la ligadura a un poder, la religación 
a la deidad, a diferencia de la divinidad $^{4}$. Si se amplía el examen a otros autores que también han querido mostrar la efectiva presencia de Dios en el espíritu humano, se ve que siguen otras rutas. Ya no hablan de un mero conocimiento indeterminado de lo divino, sino de la manifestación de Dios en ciertas dimensiones determinadas del hombre. Dios estaría presente desde siempre en la inteligencia humana, o en la voluntad, o en el sentimiento. Los argumentos a los que Zubiri se enfrenta son, desde este punto de vista, unos argumentos antropológicos que, con todos sus méritos, no le parecen estar exentos de dificultades.
Como se sabe, el nuevo punto de partida de la Edad moderna se caracteriza por efectuar un giro antropológico. Cierto énfasis antropológico también ya está presente en Agustín, pero no se desarrolla y explicita más que en autores modernos como Descartes, Kant, Hegel y Schleiermacher. Particularmente Agustín, Kant y Schleiermacher afirman que algún aspecto o rasgo humano manifiesta la presencia de Dios. Es lo que acontece con las verdades de la inteligencia humana, el hecho de la voluntad moral y el sentimiento de dependencia absoluta. Las referencias de Zubiri, en cualquier caso, son breves y sumarias. De Agustín sólo dice que

(1)

"[...] llega a Dios partiendo de que el hombre posee verdades; y toda verdad, nos dice, se apoya en una verdad subsistente, en 'la' verdad"s.

De Kant menciona apenas que

"[...] se fija en la voluntad. El hombre no sólo quiere cosas sino que ha de querer categóricamente el deber por el deber. Y esto sólo es posible si existe in re un bien en sí".

$Y$ en cuanto a Schleiermacher, asegura que

"[...] centra su atención en los sentimientos. Entre ellos, hay uno en que el hombre está embargado por el sentimiento de dependencia incondicional respecto del infinito: es el sentimiento de una realidad irracional infinita".

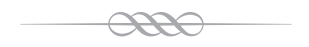

Dos conclusiones extrae Zubiri de estas rapidísimas referencias. Una, que los tres autores se concentran en algún rasgo que de hecho posee el ser humano. Y la otra, que de estos rasgos poseídos de hecho por el hombre, en cuanto tales, puede derivarse una verdad 
subsistente, o un bien óptimo, o una realidad infinita. Zubiri discute a continuación, no todo el camino intelectualmente emprendido por estos autores hacia la realidad de Dios, sino el inicio mismo de las vías antropológicas, vías que arrancan de unos determinados aspectos del ser humano. Y lo hace para poner en claro que tal arranque ha de condicionar necesariamente el término -el carácter de Dios- al que arriban estas vías.

Zubiri asevera que ninguno de estos tres autores se basa en hechos. Es la misma acusación que hace a las vías cosmológicas: no hay en el principio hechos analizables, sino hechos ya interpretados metafísicamente. ¿Cuáles son los motivos de esta acusación? Zubiri dice, para empezar, que no estamos en presencia de hechos susceptibles de análisis, porque tanto Agustín como Kant y Schleiermacher se fijan en aspectos del hombre, esto es, en ciertas características o notas que, aunque realmente le pertenecen -de eso no cabe duda alguna-, sin embargo no lo definen íntegramente. Los aspectos son solamente rasgos parciales de la realidad humana. Tomado cada uno por sí mismo, no logra expresar al ser humano por entero sino tan sólo desde alguno de sus respectos. La consecuencia inevitable de este enfoque es, entonces, su parcialidad. Con la inteligencia, la voluntad o el sentimiento no tenemos sino partes o momentos del hombre. $Y$ con fragmentos no tenemos el conjunto. Claro está que -desde la perspectiva del propio Zubiri- cada uno de estos momentos no podría ser el momento que es si no estuviese determinado por, y no fuese determinante de, los otros. Al carácter 'constructo' de la realidad humana no escapa ni siquiera la intelección, dotada como está de cierta predominancia frente a las otras notas psíquicas. Pero dicha constructividad refuerza la argumentación de Zubiri: mediante estos aspectos, tomados parcialmente y en su distinción de los demás, no se puede levantar ni una buena teoría antropológica, ni una buena teología, ni (menos) una buena fenomenología de la religión. Para ello es preciso observar la realidad humana en su unidad, que no por compleja es menos radical:

"[...] esta realidad humana es la que no aparece ni en Agustín, ni en Kant, ni en Schleiermacher. ¿Es que el hombre necesita de Dios como fundamento suyo tan sólo por ser inteligente, tan sólo por ser volente o tan sólo por sentirse de una u otra forma?"6.

Zubiri remarca, como se ve, un problema estructural de estas filoso- fías: el predominio de una facultad, sea la inteligencia, la voluntad o el 
sentimiento, cuando menos por lo que dice relación con el punto de partida del problema de Dios.

Pero, además, Zubiri agrega que en estas concepciones no hay hechos porque las ideas de la inteligencia, de la voluntad y del sentimiento que se hacen los autores mencionados son "todo menos una constatación irrecusable $\mathrm{e}^{\prime 7}$. En el caso de Agustín, Zubiri habla de una contraposición entre dos clases de verdad: la verdad par excellence, cuya morada se halla en el interior del hombre, y las verdades, plurales y tan sólo 'vero-símiles'. Es decir, en el inicio de la estrategia argumentativa de Agustín hay una dualidad, la que se establece entre dos clases de verdad cuyos modos de aparición en la inteligencia humana serían notoriamente diversos. Zubiri concluye de ello que el principio en el que se apoya Agustín no es en modo alguno la inteligencia como mero hecho. Desde el punto de vista de los hechos, asegura Zubiri, no se da ninguna contraposición de verdades en el seno de la inteligencia. Tal contraposición no puede ser más que una cierta explicación (metafísica o científica, en principio) del fenómeno intelectual. Concretamente, a Zubiri le parece indudable que el punto de partida de Agustín en esta materia es la explicación platónica y plotiniana. El dualismo acusado por Zubiri no es, pues, un dualismo que se encuentre pura y simplemente en los hechos, sino un dualismo racionalmente construido y metafísicamente justificado.
Luego, en el caso de Kant, Zubiri advierte la contraposición entre dos dimensiones de la voluntad. Hay, por un lado, las voliciones particulares, siempre plurales, local y espacialmente circunscritas. $Y$ por otro lado, hay la volición par excellence, la que es asiento de la ley moral en el espíritu humano y cuya formulación es el imperativo categórico. Si aquéllas son empíricas y están condicionadas por sus objetos, ésta es transcendental y es condicionante de su propio término objetivo. No hay compromiso posible entre una y otra voluntad, pues son dos clases tan completamente distintas de volición que su única relación es la de una contraposición perfecta. Como siempre, Kant establece como principio indiscutible la dualidad entre lo inteligible y lo sensible. Zubiri comenta, una vez más, que no estamos en presencia de un hecho sino de una explicación metafísica. La dualidad irremontable entre lo moral y lo empírico, entre lo inteligible y lo sensible, no es producto de un análisis de hechos. Pese a su persistencia en la filosofía occidental, dicha dualidad es el fruto de una espléndida construcción metafísica, que no por espléndida deja de ser una discutible construcción de la razón. En el caso de Schleiermacher, Zubiri pone de relieve el mismo problema. Existen dos tipos de sentimiento. Unos son los incontables sentimientos, en perpetuo movimiento, en los que está sumida el alma humana. Son sentimientos que, por su misma maleabilidad, están dotados de un carácter mera- 
mente condicional, pues su objeto es limitado, finito. Hay, en cambio, otro sentimiento, el sentimiento par excellence, que pertenece a otra esfera y que remite, por lo mismo, a otro mundo, o cuando menos a una dimensión esencialmente diferente de este mundo. Es, en breve, el sentimiento absoluto e incondicionado cuyo objeto es lo infinito, aquello que no tiene límite ni medida. Aquí también hay dos sentimientos bien diversos, tanto por su carácter propio como por su objeto formal. Y por tercera vez, Zubiri acusa en esta concepción la ausencia de hechos analizables y su sustitución por una dualidad radicalmente metafísica. Es decir, lejos de lo que se nos da en la aprehensión, nos hallamos nuevamente ante un punto de partida que supone ya una precisa opción racional. En los tres autores se advierten unas concepciones dualistas de la inteligencia, de la voluntad y del sentimiento. Tales concepciones dualistas hacen que Zubiri dude del carácter fáctico del punto de partida de Agustín, Kant y Schleiermacher y que tienda a pensar que en todos ellos hay unas decisiones metafísicas tomadas de antemano y unas ideas sumamente parciales y discutibles de la inteligencia, de la voluntad y del sentimiento. No se trata sólo de que las presuntas facultades sean en verdad notas constructas de la vida humana; además, se está en presencia de unos momentos que, por haber sido concebidos de manera dualista, no corresponden más que parcialmente a los fenómenos integrales de la inteligencia, del sentimiento y de la voluntad.

Zubiri añade que todos estos problemas tienen su raíz en "una determinadísima concepción del hombre $^{\prime \prime}$. Agustín, Kant y Schleiermacher están de acuerdo en que el hombre tiene un modo de ser que escapa del modo de ser de la naturaleza. El peligro es aquí el de la posibilidad cierta de desnaturalizar al hombre, de contraponerlo al cosmos y, de este modo, cortar los vínculos que hacen de él -aunque sea parcialmente- un trozo del universo: "es el hombre en y por sí independientemente de la realidad cósmica". Como esto conduce a consecuencias insostenibles, ya que el hombre es ciertamente parte del cosmos, Agustín, Kant y Schleiermacher se ven forzados a mantener una cierta dimensión natural para la existencia humana. Pero al no ser solidaria dicha dimensión natural con la dimensión propiamente humana, se adopta la estrategia de dividir la realidad del hombre, según Zubiri, "en dos zonas: una zona más o menos integrada en el cosmos, y una zona que va contra él o cuando menos sin él". De esta forma el dualismo, que ya cruza por el campo de la inteligencia, la voluntad y el sentimiento en tanto que facultades humanas realmente distintas y especificadas por dirigirse a dos clases de objetos radicalmente diversos, se reintroduce dentro de la realidad misma del hombre. Ésta parece ser la única forma de no caer en todos los problemas envuel- 
tos en una completa contraposición entre el ser humano y el universo. $\mathrm{Y}$, sin embargo, tal contraposición sigue siendo una tendencia central en Agustín, Kant y Schleiermacher. Es lo que Zubiri llama "una segregación del hombre respecto de la realidad cósmica".

Por estas razones, las vías antropológicas no parecen apoyarse en hecho alguno. La elección de alguna facultad como camino de acceso a la realidad de Dios, la distinción entre dos dimensiones completamente distintas en cada una de estas facultades, el dualismo antropológico que tiende a separar al hombre del cosmos: todos éstos no son argumentos metafísicos que puedan referirse en su punto de partida a unos hechos analizables y, por tanto, dotados de evidencia fenomenológica. Pero Zubiri lleva más allá la crítica de las vías antropológicas. Para él, no solamente hay problemas en el inicio sino que también en el término hacia el cual apuntan estas vías: "la segregación del hombre frente al mundo real, conduce a un Dios también más o menos segregado de éste ${ }^{\prime \prime}$. Es ésta, de nuevo, una idea parcial de Dios. Las vías antropológicas llevan a un Dios posibilitante e impelente respecto de la existencia humana, pero dejando de lado esos caracteres que hacen de Dios una realidad última con respecto al cosmos entero. Hay que admitir que Zubiri matiza la acusación, pues agrega que Agustín, Kant y Schleiermacher intentan -cada cual a su manera- integrar al mundo en Dios. Pero con matices y todo, estas vías tienden a conducir a un Dios segregado del universo y solamente referido al hombre como verdad subsistente, bien óptimo o término infinito del sentimiento. Justo en razón de dicha tendencia es que estos autores se ven forzados a encontrar maneras de salvar tal segregación y, así, restablecer la pertenencia del mundo a Dios y la referencia de éste a aquél en cuanto ultimidad de lo real. Las vías antropológicas, en suma, acaban en Dios como en una realidad que es punto de apoyo y fuente de posibilidades para el hombre, pero sin que entre el cosmos y Dios haya más que una relación de yuxtaposición. Las tentativas de estos tres autores por reunir a Dios con el cosmos son en verdad ensayos de convergencia a posteriori que brotan del hiato radical que ellos mismos han establecido entre uno y otro. Si Dios es último, posibilitante e impelente, sostén, raíz e impulsor, entonces las vías antropológicas no llevan a Dios en tanto que Dios.

Expuesta así la polémica, es preciso ver ahora la positiva vía antropológica emprendida por Zubiri. Como es sabido, Zubiri enfatiza la importancia de la percepción y, en general, del carácter espacial de la realidad humana. Zubiri no es materialista, pues admite que hay en el cosmos realidades que no están hechas exclusivamente de materia. No todas las realidades son pura y exclusivamente materiales ${ }^{10}$. Pero sí reconoce que todas acusan 
el carácter universal de la materia. Todas las realidades intramundanales existen en el seno de la materia y surgen en función de ella. Así, en el mundo no se actualiza ninguna realidad exclusivamente espiritual. Véase este texto del curso sobre la materia:

"no nos está dada en la realidad cósmica ninguna realidad espiritual [...] Todas las realidades cósmicas son cosas materiales, en el sentido de que, aunque no todo en ellas fuera material, sin embargo, poseen todas un momento intrínseco y formal suyo que es lo que llamamos materia [...] Ninguna cosa intramundana dada es espiritual: todo lo dado es, en una u otra forma, realidad material [...] En el orden de la realidad intramundana, la materia es un momento universal de ella [...] Toda realidad, sea o no puramente material, nace en el seno de la materia [... Además] nace en función determinante de la materia: es la materia la que determina su orto, la entrada en acción de sus posibles notas no materiales y el modo mismo de acción de ellas [... Por fin,] no sólo nace en el seno de la materia y en función determinante de ella, sino que la materia es un momento intrínseco y formal de todas las notas, aun de las no materiales"11.

Notas no materiales que nacen en el seno de la materia, en función determinante de la materia y de las cuales la materialidad es momento intrínseco y formal son la inteligencia, el sentimiento y la voluntad ${ }^{12}$. Por ejemplo, Zubiri dice que

"toda intelección humana, incluso la reflexiva, tiene [en cuanto facultad] un momento intrínseca y formalmente material [...Pero] que las facultades tengan formal e intrínsecamente un momento de sentir, esto es, de materialidad, no significa que las potencias como tales sean de estructura material. Esto sería imposible [...] Entre inteligencia, sentimiento y voluntad, por un lado, y todas las notas animales, por otro, hay una radical inhomogeneidad"13.

En general, Zubiri piensa que las notas psíquicas: inteligencia, sentimiento y voluntad, tomadas como puras potencias aún no facultadas, no son meras innovaciones sistemáticas de las estructuras 
materiales. No lo son ni en el orden funcional ni en el de las notas. No lo son en el orden funcional, porque la inteligencia, el sentimiento y la voluntad, teniendo funcionalidad, no son sin embargo funciones. La vida "es combinación funcional"14, pero la psique es más que función $y$, por ello, determina una habitud, esto es, una manera de habérselas con las cosas. La funcionalidad de las notas psíquicas, que sí existe, "se apoya en lo que ya de suyo son antes de toda funcionalidad"15. Y no son innovaciones sistemáticas en el orden de las notas, porque no consisten en cuanto potencias en unas nuevas estructuras exclusivamente materiales. Sí tienen una dimensión material en cuanto facultades. Como tales, puede decirse incluso que tienen un carácter "intrínseca y formalmente material". Por una parte, las innovaciones sistemáticas de la materia se mueven siempre en la línea de la materia. Ésta es la línea común y homogénea que reúne a las estructuras innovadas y las estructuras innovadoras. En esa línea transcurre la innovación: las nuevas notas "son siempre notas nuevas, pero de carácter eléctrico, de valencia, de posición, de calor específico, de estado físico, etc.". Lo que surge es un cuerpo nuevo, "nuevo, pero cuerpo". En cambio, inteligencia, sentimiento y voluntad no son cuerpos. Su inhomogeneidad hace de ellas notas irreductibles a la materia: "son potencias de realidad"16. La psique se apoya en la realidad y se mueve entre realidades, "y ninguna estructuración de estímulos puede dar el menor asomo de la formalidad realidad". Como facultades, la inteligencia sentiente, el sentimiento afectante y la voluntad tendente tienen estructura formalmente material. Pero las potencias intelectiva, sentimental y volitiva no tienen esa estructura material.

¿Qué consecuencia tiene todo esto? Que el hombre, por ser material, es un fragmento del cosmos. Pero que, al no ser puramente material y tener psique $y$, por ende, al estar en la realidad y determinar su propia realidad, el hombre transciende el cosmos:

\begin{abstract}
"como toda realidad sustantiva, la humana es intrínseca y formalmente respectiva, pero su respectividad humana no es respectividad de constituir un Todo, esto es, no es respectividad meramente cósmica. Es una respectividad transcósmica. Envuelve orgánicamente una estricta respectividad cósmica, pero, en su intrínseca sustantividad, el hombre está en el cosmos transcendiéndolo"17.
\end{abstract}

Es en este sentido que Zubiri dice: "enorme progreso frente al vegetal, la vida animal no es sino el remoto preludio de la vida huma$\mathrm{na}^{\prime 18}$. Tal tesis es permanente en la obra de Zubiri. Hay que hacer notar 
que entre los años 40 y parte de los 60 esta tesis antropológica mantiene un estrecho diálogo con la teología cristiana. De ahí la alusión constante a la idea de creación y el intento de hacer concordar los contenidos de ésta con los datos puramente filosóficos. No siempre es fácil, por ello, distinguir en la argumentación antropológica de estos años entre la razón teológica y la metafísica. Por ejemplo, en la sesión vigésimo octava del curso sobre "El problema de Dios", de 1948-1949, resume Zubiri su argumentación en torno al origen del hombre del siguiente modo: "de ahí que en la medida que el hombre es inteligencia sentiente, la raíz de su ser es el concurso simultáneo [...] de una creación intrínseca y de una exigencia natural". La vigésimo novena sesión del curso dice que "la evolución es, en resumidas cuentas, el movimiento de la vida para realizar dentro del árbol zoológico la imagen formal de Dios". Y en la trigésimo primera se asegura que la causalidad divina "en orden a la producción de personas" es solícita y solicitante, puesto que imprime fontanalmente en cada ser humano creado "una interna moción personal". Con todo, pese a este frecuente indiscernimiento entre teología y antropología metafísica, hemos de centrarnos en la validez que pueda tener la tesis de Zubiri con autonomía de la revelación cristiana.

Buena parte de los contenidos del texto "El origen del hombre", de 1964, provienen al menos de las lecciones vigésimo séptima y vigésimo octava del curso "El problema de Dios". La psique o alma intelectiva del hombre (de ambas maneras se expresa Zubiri) brota evolutivamente dentro de la línea específica de un homínido prehumano:

"la evolución es un proceso genético en el cual se van produciendo formas psicosomáticas específicamente nuevas desde otras anteriores y en función intrínseca transformante y determinante de éstas [...] Llamando 'psique intelectiva' a la totalidad del psiquismo humano, a diferencia de la psique no-intelectiva animal, hay que afirmar que la psique intelectiva florece intrínsecamente desde las estructuras psico-somáticas de un homínido prehumano y en función determinante y transformante de éstas, de suerte que la nueva especie, la especie humana, incluye como momento esencial suyo la conservación transformada de las estructuras morfológicas y psíquicas de aquel homínido. El hombre entero, pues, es psicosomáticamente un brote evolutivo"19.

Y sin embargo, la aparición de la inteligencia no se resuelve por la pura evolución. Nótese la alusión a una "conservación transformada", 
que parece traducción limpia del alemán Aufhebung. Zubiri también habla de elevación: "todo el instinto prehumano se halla transformado, por elevación, en el hombre" ${ }^{\prime 20}$. Para Zubiri, el psiquismo - en lo que tiene de intelectivo - no es explicable por la transformación evolutiva del animal prehumano en el homínido hominizado. Entre la inteligencia y la sensibilidad hay una diferencia no gradual sino esencial. La inteligencia supone dicha trasformación evolutiva, pero no es efectuada por ella: la transciende. $Y$ de tal modo es una innovación absoluta que debe hablarse aquí de una creatio ex nihilo:

"la mera sensibilidad no puede producir por sí misma una inteligencia: entre ambas existe una diferencia no gradual sino esencial. Por mucho que se compliquen los meros estímulos y su forma de aprehensión, jamás llegarán a constituir realidades estimulantes y aprehensión intelectiva. En este punto, la aparición de una psique intelectiva es no sólo gradual, sino esencialmente, algo nuevo. En este sentido, pero sólo en éste, decimos que la aparición de una psique intelectiva es una innovación absoluta. Esto no significa discontinuidad entre la vida de tipo animal prehumano y la vida de tipo humano en un homínido hominizado. Tampoco significa una discontinuidad estructural psíquica. La psique intelectiva conserva como momento esencial suyo la dimensión sensitiva transformada del homínido prehumano. Pero la psique humana envuelve otro momento intrínsecamente fundado en el sensitivo, pero que transciende de éste; es el momento que llamamos intelectivo. Por él no hay discontinuidad sino transcendencia; si se quiere, una continuidad en la línea de la transcendencia creadora. Y como la psique no es una adición de sensibilidad e inteligencia, sino que es una psique intrínsecamente una, resulta que la psique humana en su integridad, la psique del primer homínido hominizado, es esencialmente distinta de la psique animal del homínido antecesor del hombre. Como tal, está determinada por la transformación (por los cambios germinales) del mero homínido en hombre, pero no está efectuada por dicha transformación. Por tanto, no puede ser sino efecto de la causa primera, al igual que lo fue en su hora, la aparición de la materia: es efecto de una creación ex nihilo"21. 
Al final del texto, como se ve, Zubiri reúne a la antropología con la cosmología. Una vez más, como en "Transcendencia y física", recurre a la noción de un fundamento transcendente, de una causa primera. Pero no sólo eso. Zubiri, además, parece confundir ese fundamento metafísicamente argumentado con la idea teológica de una creatio ex nihilo. A mi modo de ver, la única manera de interpretar "El origen del hombre" es entender que en él se hace un uso exclusivamente metafísico de la idea de creación, según el cual ésta es sinónimo de fundamentación o causación de realidad, tal como en "Transcendencia y física". Es ostensible que Zubiri todavía no distingue entre fundamento y causa, como hará en su madurez. En todo caso, la creación humana es la fundación del hombre en la realidad plenaria y transcendente postulada racionalmente con independencia de la revelación cristiana. En concreto, la creación del hombre es la adición externa en un animal del alma específicamente humana por parte de la causa primera de todas las cosas. Así, la creación

"ha de ser una creación determinada por la transformación de las estructuras germinales. Esto es tan esencial como que sea ex nihilo. Se propende demasiado frecuentemente a imaginar esta creación literalmente, como una irrupción externa de la causa primera, de Dios, en la serie animal. La psique intelectiva sería una insuflación externa de un espíritu en el animal, el cual por esta adición quedaría convertido en hombre. En nuestro caso, esto es un ingenuo antropomorfismo. La creación de una psique intelectiva ex nihilo no es una adición externa a las estructuras somáticas, porque ni es mera adición ni es externa. Y precisamente por esto es por lo que a pesar de esta creación o, mejor dicho, a causa de esta creación, hay ese florecimiento genético del hombre, determinado desde las estructuras y en función intrínseca de su transformación, que llamamos evolución. La creación no es una interrupción de la evolución sino todo lo contrario, es un momento, un 'mecanismo' causal intrínseco a ella"22.

La creación no es adición externa, dice Zubiri. ¿Qué significa esto? Primero, que la aparición del hombre no es resultado de una adición sino de una cierta exigencia. La inteligencia no surge porque las estructuras bioquímicas la dispongan, sino como una exigencia biológica de viabilidad y supervivencia que arranca de esas mismas estructuras: 
"pienso que es falso que las estructuras bioquímicas sean mera causa dispositiva. Son algo más profundo. Porque en el decurso genético de esa célula llega un momento postnatal en que esas mismas estructuras bioquímicas, ya pluricelulares y funcionalmente organizadas, exigirán para su propia viabilidad el uso de la inteligencia, es decir, la actuación de la psique intelectiva [...] Por consiguiente, la propia estructura bioquímica de la célula germinal no es actualmente, pero sí virtualmente, exigitiva de una psique intelectiva [...] En consecuencia, la estructura bioquímica de una célula germinal no es mera causa dispositiva, sino algo más hondo: es una causa exigitiva de la psique humana"23.

La exigencia es originalmente bioquímica, pero la inteligencia que surge de ella reobra sobre las estructuras bioquímicas también exigitivamente. Un determinado cuerpo exige a la psique o alma intelectiva, y ésta exige un determinado cuerpo:

"este momento exigencial es numéricamente idéntico en el alma y en el cuerpo; y en esta numérica identidad exigencial consiste la unidad esencial de la sustantividad humana. De ahí que la creación de una psique intelectiva en una célula germinal no sea mera adición sino cumplimiento de exigencia biológica. Este cumplimiento es ciertamente creador [...] Pero creadoramente es cumplimiento de una exigencia biológica de la célula germinal [...] Los cambios germinales de este inmediato predecesor del hombre son causas biológicas exigitivas de la creación de una psique intelectiva de la hominización [...] Porque una especie que tuviera las estructuras somáticas transformadas que posee el homínido hominizado, y no poseyera psique intelectiva, no hubiera podido subsistir biológicamente con plena estabilidad genética; se habría extinguido rápidamente sobre la tierra [...] El hombre es, entonces, el homínido de realidades, es el homínido que siente la realidad. Su animalidad está determinada por la transformación de las estructuras germinales del antecesor del hombre. Esta transformación causal es efectora por lo que concierne a la morfología y al momento sensitivo del psiquismo, pero no es efectora sino exigencial por lo que concierne al momento intelectivo" 24 . 
Segundo, esto significa que aunque la aparición del hombre sea exigida, no es sin embargo exigida externa sino internamente. La psi- que intelectiva no sólo está en las estructuras bioquímicas que la exigen, sino que surge intrínsecamente desde ellas:

"la psique está creada desde las estructuras biológicas, brota desde el fondo de la vida misma, porque la causalidad exigitiva de las estructuras somáticas es una exigencia intrínseca" ${ }^{\prime 25}$.

De esta manera, Zubiri puede referirse a la creación como a una intrínseca eflorescencia, una natura naturans. Dios es el único fundamento posible, a la vez intrínseco y creador, de la psique humana.
Zubiri pretende vincular tan estrechamente como sea posible a la creación o fundamentación de la psique en la realidad divina con el proceso evolutivo, sin llegar a confundir la una con el otro:

"la psique no se transmite de padres a hijos. La psique no está producida por los progenitores. Pero la psique florece vitalmente en el acto generacional desde dentro de la transmisión y constitución exigitiva de las estructuras somáticas, y queda determinada por completo en su primer estado por ellas [...] Esta eflorescencia procede en su última raíz de una acción creadora, pero intrínseca a la acción genética de los progenitores. Los progenitores hacen que tenga que haber acción creadora intrínseca [...] La acción creadora [...] no es sino un mecanismo evolutivo; es un factor integrado a la transformación germinal: es el cumplimiento intrínseco de la exigencia de ésta"26.

En suma, la creación del hombre es una exigencia interna de la evolu- ción que se funda en la realidad plenaria de Dios. Dicho de otra manera:

"desde el punto de vista de la causa primera, de Dios, su voluntad creadora de una psique intelectiva es voluntad de evolución genética" ${ }^{\prime 2}$. 
Para Zubiri, el "estadio evolutivo final" ${ }^{\prime 28}$ del animal inteligente es el animal racional, el homo sapiens. Y sólo de éste se ocupa la teología; la ciencia y la filosofía, en cambio, trabajan con el animal inteligente, el animal de realidades, esto es, con el hombre en toda su amplitud, del cual el animal racional no sería sino un tipo ${ }^{29}$.

Esta íntima vinculación de la creación divina con la evolución biológica, que sin embargo no borra en absoluto la diferencia esencial entre psique inteligente y estructuras bioquímicas, es sostenida constantemente por Zubiri. En el artículo "El hombre, realidad personal" se dice que la función intelectiva de aprehender realidad es "completamente distinta de la función de sentir" ${ }^{\prime \prime 30}$. Así, "inteligir es algo irreductible a toda forma de puro sentir", aunque sin embargo "es algo intrínsecamente 'uno' [desde un punto de vista estructural] con esta última función" ${ }^{\prime \prime}$. Irreductibilidad esencial entre sentir e inteligir, unidad estructural de estas dos funciones: tal es la idea de Zubiri. Por eso agrega que esta irreductibilidad es en el fondo la que hay entre las notas materiales $y$ las notas que sobrepasan la materia. Zubiri por eso admite en el hombre una psique, un alma inteligente:

"que el hombre tenga algo irreductible a la materia, es innegable porque la inteligencia es esencialmente irreductible al puro sentir. Sin compromiso, Ilamamos a este algo 'alma'"132.

En el curso Estructura dinámica de la realidad Zubiri vuelve sobre lo mismo: la esencial irreductibilidad de la inteligencia a los sentidos implica que la realidad jamás podrá surgir de una complicación de estímulos, por elaborada que sea. Ésta es una aseveración que no puede hacer la ciencia, que sólo es capaz de afirmar "que la inteligencia surge precisamente de la animalidad y en la animalidad" ${ }^{\prime 3}$. Si el inteligir no es un mero sentir, aunque surge en el seno de la animalidad, ¿cuál es, entonces, el origen de la inteligencia? Provisionalmente, una consideración puramente intramundana que posterga la apelación a la realidad plenaria pudiera decir que el todo cósmico es una dinámica natura naturans. Y que "ejercita una causalidad efectora en la producción de las inteligencias y del psiquismo humano"34. Tal causa efectora produce evolutivamente esa innovación radical en que consiste la psique intelectiva, que no es una mera prolongación de la causalidad efectora de los demás seres (vivos o no vivos) del universo. Pero esta efección no es adicional sino intrínseca: con la evolución que innova se cumple una exigencia universal ${ }^{35}$. De ahí que, por parte de "[...] los homínidos que se hominizan, se trata de una causalidad exigitiva" ${ }^{\prime \prime 6}$. Esto último quiere decir que 
"la inteligencia no sólo no entra en juego, sino que no aparece como realidad más que en el momento en que un animal hiperformalizado no puede subsistir sino haciéndose cargo de la realidad. La inteligencia, por consiguiente, tiene ante todo y sobre todo una función biológica. Estabiliza precisamente la especie. Una especie de idiotas sería inviable"137.

Luego, en otro artículo antropológico, "El hombre y su cuerpo", $^{\prime \prime}$ se dice que el subsistema psíquico "tiene algunos caracteres irreductibles al subsistema orgánico, y en muchos aspectos (no en todos, bien entendido) tiene a veces cierta dominancia sobre éste" ${ }^{38}$. Enseguida, en "Notas sobre la inteligencia humana", Zubiri repite que la irreductibilidad de sentir e inteligir no obsta a la unidad estructural de ambos en un mismo y solo acto:

"entre el puro sentir y la inteligencia existe una esencial irreductibilidad [...Pero] en su esencial irreductibilidad, sin embargo, sentir humano e inteligir humano ejecutan conjuntamente un solo y mismo acto por su intrínseca unidad estructural" 39 .

Si en los años 60 todavía se utiliza la noción de alma, en los 70 ella deja paso definitivamente a la idea de psique $^{40}$. De ahí que haya que detenerse muy especialmente en los diversos textos de esta época ya madura, en la que — con todoaún pueden apreciarse ciertas tensiones y titubeos. El artículo "La dimensión histórica del ser humano" le da su formulación definitiva a la tesis de la estructural unidad de dos potencias irreductibles. Sin referirse al problema del origen de la inteligencia qua inteligencia más que para decir que en todo caso no es embriogenético, Zubiri establece que la unidad estructural de sentir e inteligir, a la que se ha referido tantas veces, es la unidad de dos potencias irreductibles que constituyen una sola facultad que produce actos 'a una' sentientes e inteligentes:

"ciertamente, la inteligencia, en tanto que potencia intelectiva, es esencialmente irreductible al puro sentir en 
cuanto tal. Por muchas complicaciones que otorgáramos a la potencia de sentir, esto es, a la liberación biológica del estímulo, no tendríamos nunca el más leve indicio de una potencia de 'hacerse cargo de la realidad', es decir, de una potencia intelectiva. De eso no hay duda ninguna. Pero [...] esta potencia intelectiva no está por sí misma 'facultada' para producir sus actos. No los puede producir más que si es intrínseca y formalmente 'una' con la potencia de sentir, más que si constituye una unidad metafísica con esta potencia de sentir, en virtud de la cual la inteligencia cobra el carácter de 'facultad': es inteligencia sentiente. La inteligencia sentiente no es potencia, sino facultad; una facultad 'una', pero metafísicamente compuesta de dos potencias; la potencia de sentir y la potencia de inteligir. Solamente siendo sentiente es como la inteligencia está facultada para producir su intelección. Hay que establecer, pues, una diferencia metafísica entre poder como potencia y poder como facultad. Los griegos, en su idea de la dýnamis, no lo hicieron, y menos aún los latinos. No es lo mismo tener potencia y tener facultad. Tanto es así, que la inteligencia como facultad, esto es, la inteligencia sentiente, tiene un origen genético, cosa que no sucede con la nuda potencia intelectiva. Desde el primer instante de su concepción, la célula germinal tiene todo lo necesario para llegar a ser hombre. Como la potencia intelectiva en cuanto potencia, no es resultado de una embriogenia, resulta que ya en el primer instante de su concepción, la célula germinal, además de su estructura bioquímica tiene una potencia intelectiva, sea cualquiera su origen, tema que aquí no hace al caso. La unidad metafísico-sistemática de célula germinal y de sus notas 'psíquicas' radicales es lo que muchas veces he llamado plasma germinal [...] Pero la inteligencia, como potencia, no produce ni puede producir acción intelectiva ninguna en el plasma: sería un absurdo mítico. Esa potencia no es, pues, aún facultad. Solamente lo será cuando en el curso de la morfogénesis psico-orgánica se produzca la unidad intrínseca de la potencia intelectiva y de la potencia de sentir, es decir, cuando se engendre la inteligencia sentiente, la facultad. Aunque sea quimérico pretender engendrar genéticamente la potencia intelectiva a base de ácidos nucleicos y de liberaciones biológicas de estímulos, es absolutamente inexorable la producción genética de la 
facultad de intelección justo a base de ácidos nucleicos. Como facultad, la inteligencia sentiente es rigurosamente un producto morfogenético" ${ }^{\prime 4}$.

La trilogía Inteligencia sentiente repite casi textualmente estas ideas ${ }^{42}$. Pero además agrega que esta conceptuación (dos potencias, pero una sola facultad)

"no es un hecho [...] La impresión de realidad es un hecho, y por tanto, hecho es también el sentir intelectivo o la intelección sentiente. La conceptuación de facultad estructuralmente compuesta de potencia sentiente y intelectiva es a mi modo de ver [...] la única conceptuación científica del hecho de la impresión de realidad"43.

Estamos, pues, en pleno terreno metafísico y científico. La de Zubiri ya no es una descripción de los actos de la inteligencia sentiente, sino una explicación de su estructura profunda. Esta explicación lleva a afirmar que la potencia intelectiva del hombre es "algo distinto" 44 . Por una parte, Zubiri destaca el carácter biológico de la inteligencia. Dice que la potencia intelectiva está "determinada por la hiperformalización" de las estructuras sentientes ${ }^{45}$. Sólo en unidad intrínseca y estructural con la potencia de sentir es la inteligencia una facultad. Por esto mismo dice Zubiri que la facultad intelectiva sentiente

"es una intelección que en cierto modo (aunque no exclusivamente) podríamos Ilamar cerebral. El cerebro es el órgano sentiente que por su hiperformalización determina exigitivamente la necesidad de intelección para poder responder adecuadamente. Además, el cerebro tiene una función aún más honda: mantener en vilo la intelección. Es la constitución del estado de vigilia. Finalmente, la actividad cerebral por ser sentiente, modula intrínseca y formalmente la intelección misma, la impresión de realidad. En la unidad de estos tres momentos (hiperformalización exigitiva, vigilia y modulación intrínseca) consiste el momento estructural sentiente de la intelección sentiente" ${ }^{\prime \prime 4}$.

Por otra parte, Zubiri destaca que la inteligencia es una novedad irreductible al puro sentir. Ella es una nota estructural tan peculiar que se puede decir no sólo que no es puramente estimúlica, sino que tampoco es siquiera una nota sistemática de la sustantividad humana: 
"no es una nota estimúlica complejamente elaborada. Frente a toda nota estimúlica, la inteligencia es esencialmente distinta de toda signitividad estimúlica [...] No es tampoco una nota sistemática. Se trata, por el contrario, de un elemento nuevo pero elemental, bien que exigido desde las estructuras materiales hiperformalizadas e intrínsecamente y formalmente modulado por ellas" ${ }^{\prime 4}$.

Con más detalle se explaya Zubiri en ciertos textos de 1975 recogidos en Sobre el hombre. Allí intenta justificar una vez más que el hombre es unidad psico-orgánica y, a la vez, que su potencia intelectiva, al no poder ser reducida al sentir, tiene que tener un origen no material. ¿Cómo se desarrolla la justificación? La actividad de la sustantividad humana es una sola, compleja y variable, y es en absolutamente todos sus actos, según Zubiri, "unitariamente psico-orgánica"48. El hombre se va haciendo en su entera realidad, tanto orgánica como psíquicamente ${ }^{49}$. Por este ir haciéndose "la unidad del ser del hombre es gerundial"50. El hombre no está enteramente constituido desde el principio, sino que su modo de ser es dinámico y "se va determinando" ${ }^{\prime 51}$. Tal determinación dinámica no es "una mera sucesión de momentos del ser, sino una modalización progresiva de un único $\operatorname{ser}^{\prime \prime 52}$. Y esta modalización consiste en que los niveles inferiores de realidad abren la posibilidad y la necesidad de los niveles superiores. Zubiri habla por ello tanto de una subtensión dinámica como de una exigitividad:

"genéticamente, las tres fases esenciales son animación, animalización, mentalización. Son los tres grandes momentos de este ir haciéndose de la realidad humana. Cada uno está dinámicamente subtendido por el anterior [...] La morfogénesis, en efecto, es un proceso de subtensión dinámica. La primera función no sólo abre exigitivamente desde sí misma la entrada en acción de la segunda función, sino que se mantiene intrínseca y formalmente en ésta, y modula su actividad también intrínseca y formalmente [...] El hombre empieza por estar en el mundo animadamente; pero llega un momento en que no puede estar en el mundo animadamente sino estándolo animalmente; y en otro momento no puede estar animalmente en el mundo más que estando en él mentalizadamente. Esto es, de ser animado se 
abre a ser animal, y de ser animal se abre a ser mentalizado. Recíprocamente, el ser mentalizadamente es intrínseca y formalmente un ser animalizado, y el ser animalizado es intrínseca y formalmente un ser animado [...] El ser del hombre es constitutivamente un ser único cuyo modo de ser es gerundialmente abierto" ${ }^{\prime \prime 3}$.

Precisando más las cosas, en el mismo texto Zubiri dice que la génesis es un desarrollo estructurante de la sustantividad psico-orgánica en el que pueden distinguirse una subtensión dinámica, una liberación y una incorporación. La subtensión dinámica de una función psíquica por parte de la función orgánica se explica así:

"primero, la función primera produce exigitivamente desde ella misma la entrada en acción de la segunda [...] Segundo, la función primera se mantiene estrictamente en el seno de la segunda; con lo cual la primera sostiene intrínseca y formalmente la segunda [...] Tercero, la función primera [...] modula intrínseca y formalmente, en medida desde luego variable, las cualidades que va a poner en juego la segunda función" ${ }^{\prime \prime 5}$.

La subtensión provoca una liberación. Gracias a la subtensión aparecen nuevas funciones desconocidas en el nivel inferior, que 'liberan' "para actividades de nivel superior" $^{\prime \prime 5}$. Y por la liberación de actividades superiores, la función psíquica se incorpora en la orgánica. La función segunda revierte, entonces, sobre la primera dándole nueva entidad o corporeidad a la actividad psico-orgánica del sistema entero $^{56}$. Todo esto tiene conse- cuencias de envergadura. Significa (a) que el hombre es ya persona desde el comienzo de su existencia: "desde su concepción, el hombre es [...] una realidad personal, una realidad cuya forma de realidad consiste en personeidad, porque en el plasma está ya la psique con su inteligencia ${ }^{57}$. Pero también significa (b) que en el comienzo de la existencia humana el momento psíquico de su actividad es puramente pasivo. Entonces la psique

\footnotetext{
"está en actividad no accional sino pasiva [...Su yo no es un 'yo accional'] sino un 'yo en pasividad'. Y sus determinaciones naturales son una personalidad pasiva. La expresión
} 
no significa que hay un yo que 'está' pasivo, sino que el 'es' es la pasividad misma como un modo positivo del ser personal, del estar en el mundo"58.

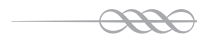

En 1975, en efecto, Zubiri piensa que las acciones de la célula germinal son solamente físico-químicas, y

que no hay aún acciones psíquicas, esto es, que la actividad psíquica -que ya existe- es puramente pasiva:

"como actividad accional no hay en la célula germinal más acciones que las físico-químicas. En ellas no interviene absolutamente para nada lo psíquico; afirmar lo contrario sería sencillamente absurdo. Pero en esta actividad 'germinal', en la que actualmente se hallan los procesos físico-químicos, se halla también en actividad todo lo psíquico, pero de un modo pasivo, es decir, como actividad pasiva. El transcurso de los procesos moleculares, en efecto, va modelando la psique, la cual está por tanto en actividad pasiva [...] En esta fase inicial hay evidentemente un predominio accional de lo orgánico. En otras etapas de la vida, en la vida adulta, sucederá lo contrario. Pero en todas ellas está en actividad el sistema entero en todas sus notas [...] La pasividad psíquica del plasma germinal no se halla limitada a lo que suele llamarse lo vegetativo y lo sensitivo sino que a mi modo de ver se extiende a todas las notas psíquicas, incluso a las intelectuales, afectivas, volitivas, etc. En esta fase germinal, bien entendido, la psique no tiene consciencia, ni intelige, ni tiene sentimientos, ni toma decisiones, etc. Pero los procesos moleculares comienzan a conformar, por ejemplo, el tipo de inteligencia, de afectividad, de voluntariedad, etc., que tendrá la psique cuando entre en acción. Esta conformación se va llevando a cabo a lo largo de todo el desarrollo psico-orgánico durante la fase pre-natal, y aún después del nacimiento" ${ }^{\prime \prime 2}$.

Sólo después de un período constituyente, (c) el hombre estará en actividad personal activa, y entonces sí que habrá acciones psíquicas:

"la prueba está en que cuando el yo se afirma accionalmente en el campo de la realidad, es un yo que 'se encuentra' consigo mismo, con lo que 'ya era' antes de ser yo en acción, antes de ninguna intervención accional suya, es decir, en pasividad. Este carácter de los actos anteriores al hacerse 
cargo de la realidad, es justo lo que [...] he llamado carácter personal de los actos naturales" 60 .

De manera (d) que, así como hay una morfogénesis orgánica, hay una morfogénesis de la misma psique:

"la psique no surge ya completamente hecha, ni en el individuo ni en la especie [...] No es que la psique en el primer instante del plasma germinal tuviera ya todas sus facultades, pero sin ejercitarlas, sino que lo que afirmo es que las facultades mismas en cuanto facultades, la psique las va adquiriendo genéticamente, bien que en distinta medida y forma [...] La inteligencia sentiente resulta ser una facultad genéticamente lograda"61.

Y sin embargo, (e) esta génesis de la inteligencia sentiente no es una génesis de la potencia intelectiva. La potencia de inteligir "está ya en el plasma"62. Lo que ocurre es que en el hombre la potencia intelectiva no está facultada para producir sus actos. Sólo está facultada cuando tiene una estructura sentiente, de manera que sólo cuando alcance esa estructura será una facultad: la inteligencia sentiente. (Lo que vale también para la otra potencia: habrá facultad sólo cuando 'cierta zona' de la potencia sensitiva alcance una estructuración inteligente.) Esto indica que, aunque la inteligencia sentiente es una estructura unitaria y una facultad única, está constituida por dos potencias, inteligir y sentir, siendo la primera esencialmente irreductible a la segunda ${ }^{63}$.

Con estas reflexiones, Zubiri ha logrado un concepto racional más maduro de la realidad humana, en el que asoma — sin apenas notarse- la necesidad de un fundamen- to plenario y transcendente para la potencia intelectiva, que a diferencia de la facultad de la inteligencia sentiente no se debe a una génesis estructurante. Pero las ideas de Zubiri al respecto siguen desarroIlándose. Prueba de ello es el texto "Génesis de la realidad humana", de 1982-1983, también incorporado en Sobre el hombre. ¿Qué es lo que dice allí Zubiri? Ante todo, que hay una génesis de la materia, una dinamicidad o dar de sí de la sustantividad material, que es la "sustantividad cuyas notas son las Ilamadas cualidades sensibles" ${ }^{64}$. Las potencialidades materiales de dar de sí son diversas. En todas ellas se produce una innovación. No son meras repeticiones sino novedades que la materia da de sí ${ }^{65}$. Una es la transformación: la "sustantividad material puede dar de sí produciendo por transformación algunas notas o partículas elementales nuevas" ${ }^{\prime 66}$. Y otra es la sistematización: una propiedad sistemática no es la propiedad distribuible en cada uno de 
los elementos del sistema, sino la que se origina de (e incumbe a) la unidad estructural de todos ellos ${ }^{67}$. Caben diversas sistematizaciones de la materia. Zubiri se refiere a la materia viva y a la materia orgánica ${ }^{68}$. La materia orgánica u organismo, a su vez, puede dar de sí, también por sistematización, otras tantas propiedades. Una es la troficidad de la sustantividad vegetal, y otra es la sensibilidad de la sustantividad animal, que a su vez puede ser simplemente genética (es la "replicación de las propias estructuras y por las propias estructuras", es decir, la generación de otros individuos dentro del mismo phylum) o evolutiva ("es la producción de un phylum 'hecho' desde otro por la modificación de este otro" $)^{69}$. Todas éstas son sistematizaciones de orden estrictamente material en las que la forma superior está fundada en la anterior. Entonces,

"no toda materia vive (hylozoísmo) y siente (pan-psiquismo). Pero por mera sistematización puede llegar a vivir y sentir. Cuando esto ocurre, la materia vive y siente exactamente al igual que pesa o calienta"70.

Pero hay algo más. La génesis de la realidad humana no consiste en una transformación ni en una sistematización de la materia ${ }^{71}$. Con los animales superiores el hombre comparte una serie de notas orgánicas o somáticas. No obstante lo cual, el hombre posee unas notas en exclusiva, que son las notas psíquicas. Veíamos que hasta los años 60 Zubiri todavía admite un principio sustancial en la sustantividad humana, que sería justamente el alma; en su plena madurez, en cambio, dice que la psique no es una sustancia ni ese principio sustancial "que vulgarmente Ilamamos 'alma'"'72. Unas y otras notas no son más que subsistemas de una sola sustantividad, que es el sistema constitucionalmente completo. Aunque en el desarrollo de la realidad humana puedan dominar unas veces las notas orgánicas y otras las notas psíquicas, la sustantividad es una actividad única y unitaria de carácter psico-somático. Cuerpo y psique no están yuxtapuestos ni unidos por agregación. Entre ambos hay una unidad sistemática, en cuya virtud

"todo lo psíquico es corpóreo, y lo corpóreo es psíquico [..., todas y cada una de las notas humanas son rigurosamente psico-somáticas, esto es, cada nota es materialpsíquica o psíquico-material"73.

Zubiri insiste en que ésta no es una concepción materialista sino 'materista' de la sustantividad humana. Y como dentro de las notas 
psíquicas la radical es la intelección, Zubiri también dice que su propia posición, nada intelectualista, sí que es 'inteleccionista'. Inteligir es aprehender realidad. En ello se distingue el hombre de todo otro animal o ser vivo: en que gracias a su intelección está, en cada uno de sus actos, en la realidad. Entre la estimulidad más complicada de un animal superior y la realidad inteligida sentientemente por el hombre hay una diferencia no gradual sino esencial. Esto es lo decisivo. Por eso la "sensibilidad pura jamás Ilegará a ser inteligencia"74. La cuestión radica en explicar cómo se genera una sustantividad radicalmente unitaria algunas de cuyas notas son esencialmente distintas de todas las demás, en el entendido de que las notas psíquicas son irreductibles a las orgánicas ${ }^{75}$. Según Zubiri, los progenitores no transmiten ni el cuerpo ni la psique. Lo único que transmiten son "los elementos germinales (espermatozoide y óvulo) que van a producir por sí mismos la célula germinal"76. Por sistematización de dichos elementos germinales se constituye la célula germinal. Y junto con ella surge, también por sistematización, la psique. Por eso es que desde el inicio hay no sólo una célula germinal sino una psique: la unidad de ambas es el 'plasma germinal"77. La psique "procede de la sistematización constitutiva de la célula germinal" ${ }^{\prime 78}$. ¿Cómo?
Zubiri rechaza ciertas ideas que alguna vez sostuvo, como la de que la célula germinal fuera causa dispositiva o exigitiva de la psique. Más que estar 'en' el cuerpo, la psique 'es-de' el cuerpo. Así, "la psique no está 'en' el cuerpo, ni está exigida por él", sino que brota procesualmente desde "las estructuras de la célula germinal misma"79. A este texto Zubiri añadió después una anotación marginal: "pero, ¿cuándo?"80. Esto muestra una indecisión de Zubiri en cuanto a si la psique efectivamente está presente desde el inicio formando unidad con la célula germinal, como se afirma en el texto. Sea de ello lo que fuere, las estructuras de la célula germinal hacen brotar las notas psíquicas. Y este hacer es constituyente: "la psique está producida 'por' la célula misma y por sus propias estructuras" ${ }^{\prime \prime 1}$. Pero como la psique (por su momento radical de realidad) es esencialmente irreductible al cuerpo, Zubiri dice que el hacer constitutivo de la célula germinal es paradójico: aunque dicha célula hace brotar desde sí misma la psique, no puede hacerla brotar 'por sí misma'. Aquí entra en juego un nuevo factor: si las estructuras de la célula germinal "hacen brotar a la psique desde sí mismas es porque algo les lleva intrínsecamente a hacerlo, mejor dicho porque algo les 'hace que hagan'"182. El hacer brotar sigue siendo un hacer de la célula germinal,

"[...] pero es un hacer que le hacen que haga. A la célula germinal se le puede hacer que haga una psique" ${ }^{\prime 83}$. 
De ahí la pregunta de Zubiri: "¿qué es esto que la lleva a hacer desde sí misma lo que por sí misma no podría hacer?" ${ }^{24}$. Zubiri emplea aquí su idea del cosmos. Considerado intramundanamente, el cosmos es la única sustantividad estrictamente tal, y respecto de ella las cosas no serían más que fragmentos o notas de la melodía dinámica universal. Claro: para la reflexión metafísica de Zubiri, que conduce a admitir la realidad divina, ni siquiera el cosmos es sustantivo, pues Dios es la única natura naturans. Pero si tomamos al cosmos como ya existente, él es la natura naturans, y las cosas, la natura naturata. La naturaleza naturante es la que hace que la célula germinal haga brotar la psique desde sí misma:

"la naturaleza naturante, por ser la unidad primaria, determina lo más intrínseco de las estructuras naturadas, y esta determinación es lo que llamamos producción. Esta acción naturante es la que produce la psique, pero no la produce independientemente de las otras cosas, esto es, no produce la psique solamente en las estructuras celulares, ni tan sólo desde ellas, sino que hace que sean ellas mismas, las estructuras celulares mismas, las que producen la psique ${ }^{\prime \prime 85}$.

Es la naturaleza naturante la que hace que la naturaleza naturada haga: "la unidad intrínseca de estos dos haceres es justamente la constitución del plasma germinal"86. La naturaleza naturante no 'utiliza' a la célula germinal como una causa instrumental, sino - dice Zubiri- absorbe en un nivel superior las estructuras de esa célula haciendo que haga desde sí misma la psique ${ }^{87}$. Esta absorción en un nivel más alto es lo que Zubiri Ilama una 'elevación': "la elevación misma consiste en que lo que hace la célula sea en las estructuras celulares mismas superior a las simples estructuras materiales" ${ }^{\prime 88}$. Y esta superioridad es el momento radical de realidad. La absorción en un nivel superior es una elevación al nivel de la realidad: "se hace trabajar a la célula en el orden de la realidad como tal"89. Entonces, las estructuras de la célula germinal hacen brotar desde sí mismas la psique porque han sido 'elevadas' a la realidad. La psique se debe a la elevación de la célula germinal a la realidad. La elevación es un acto de la naturaleza naturante distinto del acto de la célula germinal por el cual se produce la psique. Por la naturaleza naturante y no por sí misma, la célula germinal hace brotar desde sí misma a la psique ${ }^{90}$. La elevación es un acto del cosmos que pasa - esto es lo que se transmite- de progenitores a generados. Por esta elevación, el cosmos hace 
que cada célula germinal haga brotar desde sí misma una psique, una psique que sólo por un proceso de constitución genética llegará a ser intelección, sentimiento y volición, esto es, facultades de realidad ${ }^{91}$. Hay, pues, unas notas psíquicas que forman unidad con la célula germinal y que primigeniamente son anteriores a la intelección, el sentimiento y la volición, "pero anteriores dentro de una línea rigurosa de psiquismo" ${ }^{\prime 92}$. Los progenitores no transmiten la psique, pero sí transmiten la elevación de la célula germinal de la que brotará genéticamente la psique y el "primer estado psíquico" de la realidad humana recién constituida ${ }^{93}$. La génesis de la realidad humana es unitaria, es "una sola génesis psico-somática desde la concepción misma de un viviente ya psico-somático ${ }^{\prime 94}$. En el texto, como hemos visto, Zubiri piensa que "la célula germinal está elevada desde el instante mismo de la concepción" ${ }^{\prime \prime 5}$. Pero Zubiri vuelve a dudar. Al margen del texto donde dice que "lo que se concibe en la concepción es un hombre", anota esta pregunta: "la célula germinal, ¿es un hombre?" ${ }^{\prime 96}$. La psique, dice Zubiri, no se 'despide' ni se 'libera' de la materia, sino que 'conserva' (hebt auf, se diría) todas las estructuras materiales,

\section{"[...] pero como momentos de una estructura superior: la estructura de la sustantividad humana [...] Ser hombre no consiste en dejar de ser materia ni en que ésta sirva a la psique, sino que consiste en 'corporizar' la psique o 'psi- quizar' el cuerpo"97.}

La elevación tienen este rasgo desconcertante, pues hace que la materia se sobrepase a sí misma, haciendo que

\section{"[...] lo material mismo sea más que material [...] Es hacer que la materia misma esté haciendo su propia supera- ción ${ }^{\prime \prime 98}$.}

La elevación, dicho brevemente, es la potencialidad de hominización de la materia ${ }^{99}$. Para Zubiri es indudable que la materia "da de sí al hombre"100. La elevación no es una transformación ni una sistematización genética o evolutiva de la materia. La materia (por supuesto que no cualquiera, sino la de un animal hiperformalizado) puede elevarse desde sí misma, pero no por sí misma. La hominización es una potencialidad de la materia de dar de sí por otro. Consiste en "hacerle hacer a la materia desde sí misma lo que por sí misma no podría hacer"101. La materia, en suma, da de sí la intelección por elevación, y entonces "no podemos decir que la materia intelige, sino que la materia hace inteligir materialmente $\mathrm{e}^{\prime \prime 102}$. 
Los titubeos que se perciben en las dos anotaciones al texto comentado parecen pervivir en la primera parte de El hombre y Dios, cuya redacción Zubiri finalizó poco antes de su muerte, constituyendo por ende la última expresión de su concepción del hombre. En estas páginas, Zubiri repite la argumentación antropológica de siempre. Por una parte, el énfasis en la unidad de la facultad aprehensiva y del hombre mismo. La impresión de realidad es un solo acto de una sola facultad; por ser impresión es sentir animal, pero por ser de realidad, es acto de intelección. De ahí que se apele a la distinción entre las dos potencias y a la única facultad de sentir intelectivamente o de inteligir sentientemente:

"no se trata de un sensualismo. El sensualismo pretende reducir todo lo inteligido a contenidos de impresión. Y esto es absurdo. Se trata más bien de un sensismo: realidad es siempre el 'de suyo', y la forma primaria y radical de sentir el 'de suyo' es el sentir intelectivo"103.

Es cierto que el subsistema psíquico puede tener alguna dominancia sobre el subsistema orgánico, pero el único sistema es el de la sustantividad humana cuya actividad "es unitariamente psico-orgánica en todos, absolutamente todos, sus actos" ${ }^{\prime 104}$. Psique y organismo se codeterminan mutuamente, pero no como acto y potencia, "sino como momentos reales en acto y ex aequo, cuya codeterminación consiste en ser cada uno 'de' todos los demás"105. Por ello se afirma que el organismo es 'organismo-de' la psique y ésta es 'psique-de' el organismo. Lo cual no empece a seguir hablando de la consabida irreductibilidad entre sentir e inteligir, estimulidad y realidad, organismo y psique. La diferencia del hombre con el animal es esencial, la psique (no el alma o espíritu) es esencialmente irreductible al organismo, la inteligencia tampoco se puede reducir al sentir, y la

"estimulidad, por mucho que se enriquezca y se complique, no será jamás realidad. Formalidad de estimulidad y formalidad de realidad son esencialmente irreductibles"106.

Pues bien: Zubiri ahora agrega, sin precisiones cronológicas, que el embrión 'llega' a ser persona, puesto que hay un proceso de constitución genética de esa forma de realidad que es la personeidad. 
Solamente una vez que la persona se ha constituido embriológicamente empieza el hombre a cobrar figura personal. Entonces, también, vuelve a ser necesario hablar de una primera actividad pasiva de la persona recién constituida, dado que ésta no realiza actos personales sino que va recibiendo pasivamente su personalidad:

"se es persona, en el sentido de personeidad, por el mero hecho de ser realidad humana, de tener inteligencia. Ciertamente el embrión humano adquiere inteligencia y por tanto personeidad en un momento casi imposible de definir; pero llegado ese momento ese embrión tiene personeidad. Todo el proceso genético anterior a este momento es por esto tan sólo un proceso de hominización. Al tener, llegado su momento, esta forma de realidad, ciertamente el embrión no ejecuta todavía actos personales; y podría pensarse entonces que esa personeidad carece aún de personalidad. Pero no es así, porque la personeidad no se configura tan sólo ejecutando actos, sino también recibiendo pasivamente la figura que en esa personeidad decantan los procesos genéticos que se ejecutan por el viviente humano en su proceso de hominización. Cuando este embrión llega a tener inteligencia va cobrando personalidad pasivamente. En definitiva, desde que el embrión humano tiene esa forma de realidad que es la personeidad, esta personeidad se va siempre modelando a lo largo de toda la vida humanamente constituida"107.

La génesis del hombre es un proceso de hominización. Por eso se puede admitir que a partir de cierto momento de la vida intrauterina el embrión se constituye como persona. Si Zubiri tendía a seguir la idea tradicional según la cual la persona es resultado inmediato de la concepción, al final de su vida parece aceptar — de acuerdo con los dicta de la embriología- que hay una génesis personal del hombre "en un momento casi imposible de definir" del desarrollo embrio- nario. Pero esto, con todas las implicaciones metafísicas y éticas que pueda tener, no altera la tesis básica: que en el hombre hay una novedad excepcional respecto de la animalidad. Claro que esta novedad se puede explicar recurriendo a las estructuras materiales que hacen desde sí mismas la psique. $Y$ es que, como decía en los años 70, no hay problema en admitir que la facultad que es la inteligencia sentiente sea un producto morfogenético. Empero, ése es un punto 
de vista penúltimo que no agota la cuestión. Desde el punto de vista último o definitivo al que la razón siempre aspira (aunque no sea más que por meras aproximaciones), no se puede entender la emergencia de la potencia intelectiva con el mero recurso a la materia, ya que ésta no es capaz de hacer por sí misma la psique intelectiva. La idea de una elevación, o comoquiera que se la llame, sigue siendo insustituible ${ }^{108}$.

Éstos son, en fin, los desarrollos de Zubiri en torno al concepto racional del hombre. En todo momento se insinúa el papel de la realidad plenaria y transcendente, que es la que eleva a la materia para que pueda dar de sí la intelección. El desarrollo filogenético y ontogenético del hombre es una complicada cuestión evolutiva y embriológica, pero si en ella la cohesión sistemática entre organismo y psique resulta crucial, también lo es explicar por qué hay en el hombre esas notas psíquicas que lo abren a la realidad y que desbordan las capacidades materiales específicas e individuales. Esta explicación ha de dar razón de que dos conjuntos de notas toto caelo irreductibles hayan constituido un solo sistema sustantivo que es 'a una' material, animal, personal y libre. Incluso en los textos más maduros de Zubiri, que ya no hablan de alma o espíritu y que enfatizan las condiciones materiales de la intelección y de la entera realidad humana, nunca deja de salvarse la irreductibilidad del inteligir al sentir y de la psique inteligente al organismo. Sea exigencia, subtensión dinámica, liberación, conservación que supera o elevación que hace que la materia haga algo que no está 'en' la materia sino que es 'de-la' materia sin ser material: en cualquier caso, la interpretación racional esbozada por Zubiri intenta destacar la innovación esencial que el hombre introduce en el cosmos. Tal innovación es la que pide explicación, que si penúltimamente puede recurrir a las estructuras físicas, químicas y biológicas del universo, a la larga y en definitiva ha de postular un fundamento que ya no es material y relativo sino simple $y$ absolutamente absoluto. En efecto, podrá decirse que la psique humana brota de la célula germinal porque el cosmos es natura naturans que hace que la materia haga su propia superación, pero esto no impedirá sino que llevará inexorablemente a postular que la célula germinal está elevada a la realidad y hace brotar a la psique desde sí misma pero no por sí misma sino por el cosmos, y que el cosmos, que respecto de cada cosa y de la célula germinal es naturante, es sin embargo en sí mismo como realidad una natura naturata. $Y$ es que, asegura Zubiri, el cosmos no es real por sí mismo.

En este punto se reúnen las argumentaciones cosmológica y antropológica, y a la insuficiencia real del cosmos se agrega ahora la insuficiencia real de la materia y del sentir animal. La argumentación antropológica desemboca no en un materialismo sino en algo distinto: 
en un materismo que admite la elevación de la materia para que dé de sí desde sí misma lo que ella por sí misma no puede hacer. La elevación intenta conceptualizar por qué la materia hace desde sí misma lo que por sí misma no puede hacer. Por esto es por lo que la argumentación antropológica de Zubiri no es fisicalista o emergentista, sino más bien dualista. Aunque no por ello deba ser identificada con ciertas tesis dualistas y confesadamente teológicas que hacen que Dios, como verdadero autor, 'introduzca' o 'inyecte' el alma en el cuerpo procreado por los padres; para Zubiri, la psique humana se desarrolla desde la materia, pero desde una materia elevada o superada, ya que la materia por sí misma no puede hacer una potencia intelectiva. Es esta elevación de la materia la que lleva a la realidad plenaria que explica la potencia elemental e irreductible de inteligir y consiguientemente la absoluta novedad que el hombre constituye. Entonces, la permanente afirmación de que el inteligir es irreductible al sentir

\section{Bibliografía}

A. García Suárez (1995), "Qualia: propiedades fenomenológicas", en F. Broncano (ed.), Enciclopedia Iberoamericana de Filosofía Vol. 8: La mente humana (Marid, Trotta), pp. 353-383.

D. Gracia (1986), Voluntad de verdad. Para leer a Zubiri (Barcelona, Labor). es la prueba que ofrece Zubiri para justificar la existencia de la realidad divina. Y como esta irreductibilidad implica que la apertura a la realidad define al hombre en cualquiera de sus dimensiones, en todos sus actos, en la habitud con la que se enfrenta a las cosas y en cada una de sus facultades y estructuras, la existencia de Dios será la admisión no sólo de la realidad plenaria última y sostenedora, sino de la realidad posibilitante e impelente que es raíz e impulso de la personalidad humana. Contra las clásicas argumentaciones de Agustín, Kant y Schleiermacher, hay que decir que la radical innovación que constituye el hombre no es puramente intelectiva, sentimental o volitiva, sino que justo por ser intelectiva es a la vez sentimental y volitiva, cualificando así todas sus peculiaridades personales, morales, sociales e históricas. Y entonces Dios será no sólo lo máximamente inteligido, sentido o querido, sino la realidad última, posibilitante e impelente que sostiene, radica e impulsa, la realidad plenaria concreta, única y personal.

D. Gracia (2004), "La antropología de Zubiri", en J. A. Nicolás y O. Barroso (eds.), Balance y perspectivas de la filosofía de $X$. Zubiri (Granada, Comares), pp. 87-116.

E. Solari (2008), "El problema de Dios según Heidegger", en Cuadernos Salmantinos de Filosofía Vol. XXXV, pp. 279-396. 
E. Solari (2009), "El argumento cosmológico de Zubiri", en Revista de Filosofía. Universidad de Chile Vol. 65, pp. 115-141.

X. Zubiri (1948-1949), "El problema de Dios" (inédito curso oral de 33 lecciones cuya transcripción mecanografiada se halla en la Fundación Xavier Zubiri de Madrid).

X. Zubiri (1962), Sobre la esencia (Madrid, Sociedad de Estudios y Publicaciones).

X. Zubiri (1964), "Transcendencia y física", en Gran Enciclopedia del Mundo Vol. 18 (Bilbao, Durvan), cols. 419-424.

X. Zubiri (1972-1973), "La dimensión histórica del ser humano", en VV.AA., Realitas Vol. I Madrid, Sociedad de Estudios y Publicaciones), pp. $11-64$

NOTAS

1 Véase, por ejemplo, el caso de D. Gracia, uno de los más autorizados intérpretes de esta filosofía, quien, al mostrar los esbozos racionales teístas de Zubiri, apenas menciona su argumento cosmológico, sin decir prácticamente nada de sus prolongadas reflexiones antropológicas al respecto ni de su tratamiento de las cuestiones que tocan a la teodicea (cf. Gracia 1986: 222229 y 2004).

2 Para una reconstrucción del mismo, vid. Solari (2009).

3 Zubiri (1964: 422).
X. Zubiri (1980), Inteligencia sentiente: Inteligencia y realidad (Madrid, Alianza).

X. Zubiri (1982), Siete ensayos de antropología filosófica (Bogotá, USTA).

X. Zubiri (1983), Inteligencia sentiente: Inteligencia y razón (Madrid, Alianza).

X. Zubiri (1984), El hombre y Dios (Madrid, Alianza).

X. Zubiri (1986), Sobre el hombre (Madrid, Alianza).

X. Zubiri (1989), Estructura dinámica de la realidad (Madrid, Alianza).

X. Zubiri (1992), Sobre el sentimiento y la volición (Madrid, Alianza).

X. Zubiri (1996), Espacio. Tiempo. Materia (Madrid, Alianza).

X. Zubiri (1997), El problema teologal del hombre: cristianismo (Madrid, Alianza).

4 Para una primera idea en torno a las nociones de religación, Dios y religión en Zubiri, vid. Solari (2008: 386-390).

5 Zubiri (1984: 124). Mientras no se diga lo contrario, las siguientes citas de Zubiri corresponden a la misma página.

6 Zubiri (1984: 125).

7 Zubiri (1984: 125).

8 Zubiri (1984: 126). Mientras no se diga lo contrario, las siguientes citas de Zubiri corresponden a la misma página.

9 Zubiri (1984: 126-127). 


\begin{tabular}{|c|c|}
\hline 10 & Vid. Zubiri (1996: 411-413). \\
\hline 11 & Zubiri (1996: 376, 386 y 404-405). \\
\hline 12 & Vid. Zubiri (1996: 405-406). \\
\hline 13 & Zubiri (1996: 410-412; vid. 405-413). \\
\hline 14 & Zubiri (1996: 411). \\
\hline 15 & $\begin{array}{l}\text { Zubiri (1996: 412). Mientras no se } \\
\text { diga lo contrario, las siguientes citas } \\
\text { de Zubiri corresponden a la misma } \\
\text { página. }\end{array}$ \\
\hline 16 & $\begin{array}{l}\text { Zubiri (1996: 412-413). Mientras no } \\
\text { se diga lo contrario, las siguientes } \\
\text { citas de Zubiri corresponden a esta } \\
\text { última página. }\end{array}$ \\
\hline 17 & Zubiri (1996: 426). \\
\hline 18 & Zubiri (1996: 699). \\
\hline 19 & Zubiri (1982: 44-45). \\
\hline 20 & Zubiri (1982: 44-45). \\
\hline 21 & Zubiri (1982: 46-47). \\
\hline 22 & Zubiri (1982: 47). \\
\hline 23 & Zubiri (1982: 48). \\
\hline 24 & Zubiri (1982: 49-51). \\
\hline 25 & Zubiri (1982: 51). \\
\hline 26 & $\begin{array}{l}\text { Zubiri (1982: 52-53). Esto es algo } \\
\text { que ya está esbozado en Sobre la } \\
\text { esencia: "los padres no transfieren } \\
\text { el espíritu a sus hijos, pero ello no } \\
\text { obsta para que el hijo esté real y } \\
\text { verdaderamente engendrado por } \\
\text { los padres. Pues bien, análogamen- } \\
\text { te, aunque el proceso genético no } \\
\text { produzca el espíritu humano por } \\
\text { transmutación del psiquismo animal, } \\
\text { sin embargo, continúa siendo verdad } \\
\text { que la especie humana es el término } \\
\text { de una evolución zoológica" (1962: } \\
\text { 262). Y antes incluso en el curso } \\
\text { "Acerca de la voluntad": "es el cuer- } \\
\text { po el que con sus estructuras va mo- } \\
\text { delando a radice la actividad anímica. }\end{array}$ \\
\hline
\end{tabular}

Realmente, para una diferenciación celular en el plasma germinal no hace falta para nada el espíritu humano. Sin embargo, el espíritu está allí. ¿Haciendo qué? Nada. Padeciendo. Recibiendo precisamente la forma de sus estados mentales, que el despliegue del plasma germinal va a imprimir en ellos. De ahí que si es falso, evidentemente, que los padres den el alma a su hijo, es absolutamente verdadero que determinan en él su primer estado mental" (1992: 58).

Zubiri (1982: 53-54). Parejamente se expresa en un curso parcialmente teológico de 1971, cuando reafirma que la fundamentalidad divina se inserta en la evolución como una exigencia interna del psiquismo humano. Dice: "Dios no es una especie de definidor, de dictador teologal o cósmico, diciendo que haya hombres, y que haya cada uno de ellos. Dios ha hecho que la creación se vaya en cierto modo haciendo divinamente. Ahí está el modo divino: por evolución” (1997: 225-226). En este sentido, y sólo en éste, es cierto que el origen del cuerpo y de la psique sea material y que "el curso de la evolución material hasta la mente humana es justamente la marcha desde la pura materia hasta la libertad" (vid. 1997: 229).

28

29

Zubiri (1982: 54).

Vid. Zubiri (1982: 40-43). "El origen del hombre" termina, en franco abandono de la argumentación metafísica, con una alusión al servicio teológico que puede prestar la noción de elevación, pero ya no esa elevación exigida e interna de que hemos tratado sino la elevación teologal interna no exigida que especifica a la fe cristiana: "el animal 
racional fue elevado a un estado que llamaríamos 'teologal' descrito por el Génesis y por san Pablo. Ya no es mero animal racional sino animal racional teologal. Es una elevación no exigida, pero sí intrínseca ( $a b$ intrinseco): por esto se dice que es mera elevación” (1982: 54).

Zubiri (1982: 66-67).

Zubiri (1982: 67).

Zubiri (1982: 72).

Zubiri (1989: 214-215; vid. 219).

Zubiri (1989: 214-215).

Vid. Zubiri (1989: 212-213, 215-216 y 218).

Zubiri (1989: 214).

Zubiri (1989: 213).

Zubiri (1982: 90).

Zubiri (1982: 113-115).

Es algo que ha destacado Gracia (vid. 2004: 103-104).

Zubiri (1972-1973: 154-155).

Vid. Zubiri (1980: 89-92).

Zubiri (1980: 91-92).

Zubiri (1980: 96).

Zubiri (1980: 96).

Zubiri (1980: 96-97). Para una anticipación de esta idea en algunos textos anteriores, vid. Zubiri (1982: 67-68 y 1986: 510-512 y 523).

47 Zubiri (1980: 97; sobre la exigitividad, vid. 72). El volumen Inteligencia y razón agrega que, "por muy últimas que sean, las células o los componentes celulares de un organismo humano no son lo que determina que el organismo tenga un modo último de ser personal": Zubiri (1983: 115).
Zubiri (1986: 482).

Vid. Zubiri (1986: 166).

Zubiri (1986: 167).

Zubiri (1986: 166).

Zubiri (1986: 166).

Zubiri (1986: 166-167; vid. también 497-506).

Zubiri (1986: 508).

Zubiri (1986: 508-509).

Vid. Zubiri (1986: 509).

Zubiri (1986: 163-164). "La psique es un momento constitutivo y no consecutivo del plasma germinal" (1986: 496; vid. 510).

Zubiri (1986: 164).

Zubiri (1986: 486-488; vid. también 490-492 y 529$)$.

Zubiri (1986: 164).

Zubiri (1986: 489, 496 y 502).

Zubiri (1986: 503).

Vid. Zubiri (1986: 503-504 y 515).

Zubiri (1986: 450).

Vid. Zubiri (1986: 475).

Zubiri (1986: 451; vid. también 475).

Vid. Zubiri (1986: 447).

Vid. Zubiri (1986: 452-454 y 475).

Zubiri (1986: 454).

Zubiri (1986: 454-455).

Vid. Zubiri (1986: 475).

Zubiri (1986: 455).

Zubiri (1986: 456 y 474).

Zubiri (1986: 460).

Vid. Zubiri (1986: 460).

Zubiri (1986: 461). 


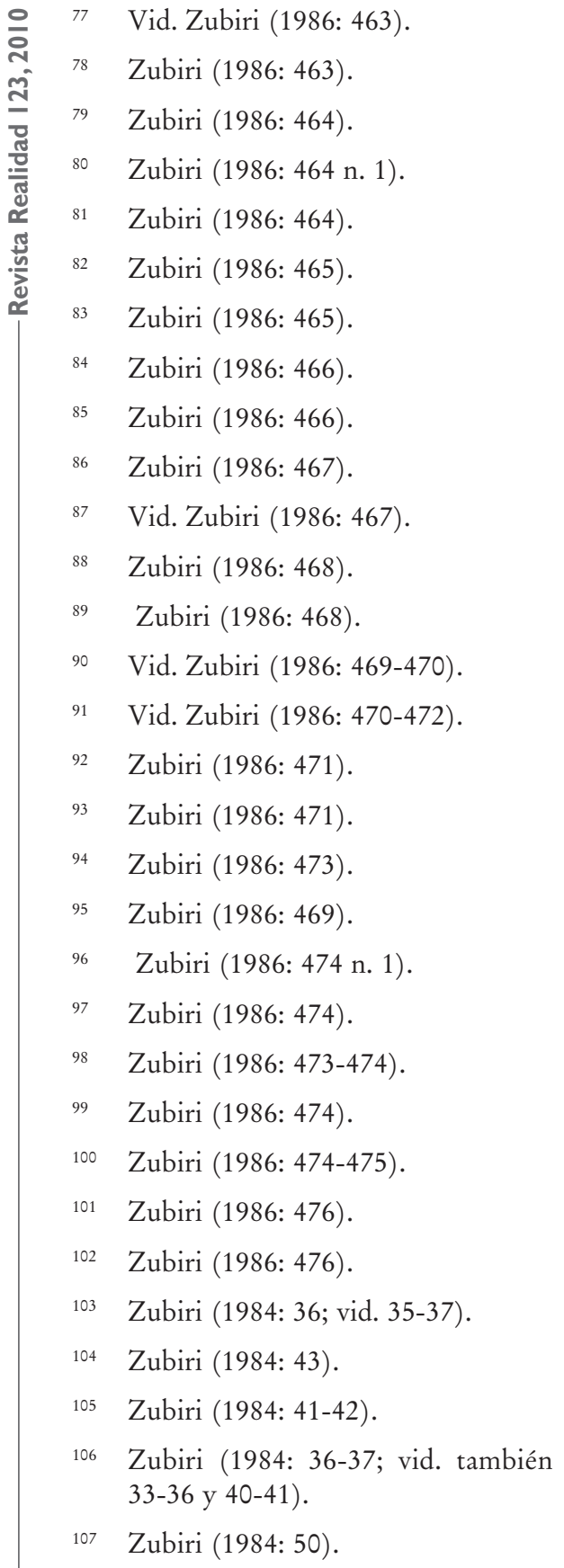

108 A la luz del texto antes citado de $E l$ hombre y Dios, Gracia ha dicho que la inteligencia es una nota que surge genéticamente por sistematización material "como consecuencia de la elevación” (2004: 113). Esto podría parecer insostenible, pues Zubiri en Inteligencia y realidad asegura que la inteligencia no es una nota estimúlica ni sistemática sino elemental. La única forma de hacer concordar una cosa con la otra es entender que la génesis es de la facultad de sentir intelectivamente, mientras que la elementalidad es de la inteligencia qua potencia. Así, puede tener sentido añadir que el resultado del proceso constituyente de la sustantividad humana "sería una nota sistemática nueva, que es lo que llamamos psiquismo específicamente humano o inteligencia. Ese proceso es estrictamente material o fisicoquímico, de tal manera que son los elementos materiales los que dan 'desde sí mismos’ lugar a la psique específicamente humana”, si bien lo hacen porque están 'elevados', única forma de explicar los caracteres inmateriales o espirituales de la psique: Gracia (2004: 115). Esta interpretación cree ser más fiel a lo que Zubiri terminó pensando en sus últimos años, algo que constituiría una suerte de 'emergentismo por elevación'. El problema es que dicha interpretación lleva a decir que "ya no tiene sentido hablar de una potencia intelectiva pura" (2004: 113), cosa que -como hemos visto- no tiene respaldo en Zubiri, ni siquiera al final de su vida. $\mathrm{Y}$ es que, metafísicamente hablando, la potencia intelectiva es ese ingrediente o momento de la facultad de inteligencia sentiente que no se explica más que por una elevación de la materia, y que por tanto no 
se puede reducir a una morfogénesis puramente material. Así, pues, por mucho que Zubiri enfatice la unidad estructural entre cuerpo y psique intelectiva y acepte que ésta emerge materialmente desde aquél, su postura sigue siendo dualista, pues todo el proceso fisicoquímico cuyo sujeto material es el cosmos ya está elevado, siendo esta elevación transcendente e irreductible al cosmos. Por este peculiar dualismo que admite la génesis material de la inteligencia sentiente, Zubiri puede aproximarse a la también peculiar tesis de Searle, que alega no ser ni dualista ni materialista, sin empero identificarse con él, precisamente porque no es dualista y rechaza todo recurso a una intervención divina (vid. Searle 2006: 63-64 y 162-167, el cual -dicho sea de paso- ha sido considerado de todos modos como un dualista, al menos en el sentido del dualismo de propiedades: vid. García Suárez 1995: 380-381). Para Zubiri, la génesis de la facultad de inteligencia sentiente es material, pero solamente porque una intervención divina 'eleva' a la materia para que pueda dar desde sí misma la potencia intelectiva. 